\title{
Sorption of Arsenic and Heavy Metals Using Various Solid Phase Materials
}

\author{
Woosik Jung, Young Kyu Park, Ju-suk An, Ji Young Park, and Hyun Je Oh
}

\begin{abstract}
A composite adsorbent was synthesized by immobilizing ferric oxide or three different iron oxides into alginate beads (HFOAB) for the removal of arsenate [As(V)] and heavy metals from aqueous phase. Sorption studies were conducted on single and binary sorbate systems, and the effects of contact time, initial adsorbate concentration, and $\mathrm{pH}$ on adsorption performance of HFOAB were monitored. The sorption process for $\mathrm{As}(\mathrm{V})$ and $\mathrm{Cu}(\mathrm{II})$ reached an equilibrium state within $240 \mathrm{~h}$ and $24 \mathrm{~h}$. The maximum sorption capacity of $\mathrm{As}(\mathrm{V})$ was $13.8 \mathrm{mg} \mathrm{g}^{-1}$ after $168 \mathrm{~h}$. The effect of arsenic species on $\mathrm{Cu}$ (II) sorption was insignificant. The adsorption of $\mathrm{As}(\mathrm{III})$, $\mathrm{As}(\mathrm{V})$, and $\mathrm{Cu}(\mathrm{II})$ followed pseudo second order kinetics. Kinetic studies showed that adsorption process reached equilibrium within $8 \mathrm{~h}$ at an initial concentration of $10 \mathrm{mg} / \mathrm{L}$. $\mathrm{Pb}$ (II) and $\mathrm{Cd}$ (II) showed a greater sorption capacity on NCBs, which might be due to sorption sites provided by the immobilized GNC. The sorption affinity of divalent metal ions on NCB was in the following order: $\mathrm{Pb}=\mathrm{Cu}=\mathrm{Cd}>\mathrm{Zn}=\mathrm{Ni}>$ Co $>M n$. The study demonstrates that the synthesized sorbent could be useful for the simultaneous removal of both anionic and cationic contaminants from wastewater.
\end{abstract}

Index Terms-Adsorption, alginate beads, hydrous ferric oxide, nano carbon, arsenic, heavy metals.

\section{INTRODUCTION}

Effective removal of arsenic and heavy metals from aqueous solution is an important issue in the protection of the environment and also in public health. Because heavy metal ions are not biodegradable, must be removed from contaminated water via physical or chemical processes, such as chemical precipitation, membrane filtration, ion exchange and adsorption [1], [2]. Biological adsorbents are currently being considered as cost effective and efficient alternative materials for the removal of toxic metal contaminants [3].

Arsenic has been detected in soils, and surface and ground waters at potentially toxic concentrations due to natural sources, mine drainage, and arsenic-based pesticides [4]. Elevated and undesirable levels of arsenic in groundwater have been reported globally [5]-[7]. To avoid health issues associated with arsenic in drinking water, the World Health Organization (WHO) has recommended a maximum contamination limit of $10 \mu \mathrm{g}$ As L-1. In view of the above issues, development of a reliable, effective, and economical treatment technology for arsenic removal from groundwater is urgently needed. Numerous studies have quantified and

Manuscript received March 27, 2016; revised August 21, 2016.

The authors are with the Korea Institute of Construction Technology (KICT), 283, Goyangdae-Ro, Ilsanseo-Gu, Goyang-Si, Gyeonggi-Do, 411-712, Korea (e-mail: woosik@kict.re.kr, ykpark@kict.re.kr, jusuk@kict.re.kr, pjy237@kict.re.kr, hjoh@kict.re.kr). modeled $\mathrm{As}(\mathrm{V})$ and $\mathrm{As}(\mathrm{III})$ sorption onto amorphous iron oxides, goethite, lepidocrocite, and hematite. Both $\mathrm{As}(\mathrm{V})$ and As(III) are sorbed strongly to iron oxide; however, the sorption behavior of arsenic is dependent on its oxidation state and the mineralogy of the iron oxides [8]

Alginate is known for its metal binding properties whereby ion exchange between metal ions can occur [9]. It has been widely reported that the sorption of heavy metal ions onto biosorbents takes place via a specific ion exchange mechanism involving the replacement of protons, alkali, alkaline earth, or other cations by heavy metal ions [10]. Even though alginate has mainly been used as an immobilization agent, it plays a prominent role in metal sorption and has been reported to have excellent sorption capacity towards several heavy metal ions. In recent studies, the alginate sorption capacity has been shown to greatly exceed that of the actual sorbents immobilized in its matrix [11]. Due to this property, previous studies of alginate have not only been concerned with the mechanism of metal binding [12] and its metal sorption properties [13], [14] but also with its role as a composite membrane component [15].

Recently, nano-adsorbents such as iron oxides, titanium oxides, nickel oxide, iron-copper binary oxide, and zirconium oxides have demonstrated excellent arsenic removal efficiency [16], [17].

The aim of this study was to develop a new adsorbent by immobilizing the graphite nano carbon (GNC) or hydrous ferric oxide (HFO) on alginate matrix for the efficient removal of arsenic and heavy metals. Kinetics sorption experiments, isotherm sorption experiments, and the effect of contact time, initial adsorbate concentration, and $\mathrm{pH}$ on the adsorption performance of adsorbents were illustrated using the developed sorbent. The developed sorbent could be effectively utilized to simultaneously removal of contaminated water with cationic and anionic contaminants.

\section{MATERIALS AND METHODS}

\section{A. Chemical and Reagents}

All chemicals and reagents used in the experiments were analytical grade unless otherwise specified. Sodium alginate was purchased from Sigma Aldrich and was used without further purification. Stock solutions (1000 $\left.\mathrm{mg} \mathrm{L}^{-1}\right)$ of $\mathrm{As}(\mathrm{V})$ was prepared by dissolving sodium hydrogen arsenate heptahydrate $\left(\mathrm{Na}_{2} \mathrm{HAsO}_{4} \cdot 7 \mathrm{H}_{2} \mathrm{O}\right.$, Sigma Aldrich, USA) in deionized (DI) water followed by further dilution as required. Stock solutions of $\mathrm{Pb}(\mathrm{II}), \mathrm{Cd}(\mathrm{II}), \mathrm{Zn}(\mathrm{II}), \mathrm{Ni}(\mathrm{II}), \mathrm{Mn}(\mathrm{II})$ and $\mathrm{Co}$ (II) $(1,000 \mathrm{mg} / \mathrm{L})$ were prepared with reagent grade in deionized (DI) water, respectively, which were further diluted 
to achieve the desired concentration. Calcium chloride $\left(\mathrm{CaCl}_{2}\right), \mathrm{HCl}$, and $\mathrm{NaCl}$ were purchased from Sigma-Aldrich.

\section{B. Preparation of Adsorbents}

Two grams of Na-alginate were dissolved in $1,000 \mathrm{~mL}$ of DI water under continuous magnetic stirring to prepare a homogeneous solution of $1 \mathrm{~g}$ of hydrous ferric oxide. This mixture was added dropwise into calcium chloride solution $(0.05 \mathrm{M})$ using a $50 \mathrm{~mL}$ syringe with a $1.7 \mathrm{~mm}$ needle to form hydrous ferric oxide alginate beads (HFOAB). The HFOABs were washed several times with DI water to remove excess calcium ion and were finally dried at room temperature for 24 h. Graphite nano-carbon (GNC), with an average diameter of $50 \mathrm{~nm}$, was prepared according to the procedure reported by Kim et al. [18]. In brief, electrical current with 50-60 V and $150 \mathrm{~mA}$ was applied using graphite cathode electrodes in a reactor containing de-ionized (DI) water for GNC preparation A colloidal solution $(\mathrm{pH} \mathrm{3})$ of $\mathrm{GNC}$ at $3,000 \mathrm{mg} / \mathrm{L}$ was obtained following $15 \mathrm{~min}$ of electrolysis. The calcium alginate beads employed as an adsorbent were prepared by the dropwise addition of sodium alginate $(3 \% \mathrm{w} / \mathrm{v})$ into $0.05 \mathrm{M}$ calcium chloride solution under magnetic stirring for $12 \mathrm{~h}$, to obtain a homogeneous colloidal suspension. The suspension was then added dropwise into $1,000 \mathrm{~mL}$ of $0.05 \mathrm{M} \mathrm{CaCl}_{2}$ solution using a $5.0 \mathrm{~mL}$ syringe with a $1.7 \mathrm{~mm}$ diameter needle to form NCBs. Ca-alginate beads formed upon contact with the cross-linker solution and were left overnight to stabilize. The excess cross-linker solution was removed, and the beads were washed several times with deionized water. The diameters of both beads were approximately $3.0 \mathrm{~mm}$.

\section{Sorption Experiments}

Sorption experiments were carried out in $50 \mathrm{~mL}$ glass vials at $25^{\circ} \mathrm{C}$ and $100 \mathrm{rpm}$ in batch mode. Standard solutions of heavy metals, $\mathrm{As}(\mathrm{V})$ and $\mathrm{Cu}(\mathrm{II})$ were prepared by diluting stock solution $\left(1000 \mathrm{~g} \mathrm{~L}^{-1}\right)$, followed by adjustment of the $\mathrm{pH}$ to 5 with $0.1 \mathrm{M} \mathrm{HCl}$ or $\mathrm{NaOH}$. Kinetic experiments of $\mathrm{Pb}$ (II), $\mathrm{Cu}(\mathrm{II}), \mathrm{Cd}(\mathrm{II}), \mathrm{Zn}(\mathrm{II}), \mathrm{Ni}(\mathrm{II}), \mathrm{Co}(\mathrm{II})$ and $\mathrm{Mn}(\mathrm{II})$ were performed by equilibrating $0.05 \mathrm{~g}$ of graphite nano carbon beads with $20 \mathrm{~mL}$ solutions of adsorbate containing $20 \mathrm{mg} \mathrm{L}^{-1}$ of heavy metals. The adsorption performance of NCBs with various heavy metal ions was studied in batch mode and the results were compared with ABs. The experiments were performed in $50 \mathrm{~mL}$ capped glass tubes. The sorbate solutions $(20 \mathrm{~mL})$ at desired concentrations were equilibrated with 0.2 $\mathrm{g}$ of sorbents (ABs and NCBs) in a shaker operated at $100 \mathrm{rpm}$ The suspensions were filtered after equilibrium has been attained.. The equilibrium time for sorption experiments was estimated from the kinetics experiments. The effect of contact time on $\mathrm{As}(\mathrm{V})$ adsorption on various solid phase iron oxides was investigated. Experiments were conducted in $20 \mathrm{~mL}$ of solution with initial concentrations of $10 \mathrm{mg} \mathrm{L}^{-1} \mathrm{As}(\mathrm{V})$ with a mixing rate of $100 \mathrm{rpm}$ at $25^{\circ} \mathrm{C}$. Simultaneous $\mathrm{As}(\mathrm{V})$ and $\mathrm{Cu}$ (II) kinetics experiments were carried out with $20 \mathrm{~mL}$ solutions of $10 \mathrm{mg} \mathrm{L}-1 \mathrm{As}(\mathrm{V})$, and $20 \mathrm{mg} \mathrm{L}^{-1} \mathrm{Cu}(\mathrm{II})$ using $0.02 \mathrm{~g}$ of HFOAB. Blanks (absence of sorbent) were run to ascertain the absence of chemical precipitation in the binary system. Experiments were performed in duplicate, and the sorption capacity at equilibrium (qe, $\mathrm{mg} \mathrm{g}-1$ ) was determined using Eq. (1)

$$
q_{e}=\frac{\left(C_{o}-C_{e}\right) V}{m}
$$

where $\mathrm{Co}$ and $\mathrm{Ce}$ are the initial and equilibrium concentrations (mg L-1), respectively, $\mathrm{V}$ is the volume of solution (L), and $\mathrm{m}$ is the mass of sorbent (g). After reaching equilibrium, the suspensions were filtered, and the residual metal concentration in the filtrate was determined using inductively coupled plasma atomic emission spectroscopy (ICP-AES, Perkin Elmer 3000 DV, USA).

\section{RESULTS AND DISCUSSION}

\section{A. Effect of Contact Time with HFO Immobilized Alginate Beads}

Experiments were carried out to examine the adsorption of $\mathrm{As}(\mathrm{V})$ on HFOAB, GtAB and MtAB with contact time (Fig. 1). The effect of contact time on the adsorption of $\mathrm{As}(\mathrm{V})$ onto HFOAB, GtAB and MtAB at initial concentrations of 20.0 $\mathrm{mg} \mathrm{L}^{-1}$ is shown in Fig. 1. The removal efficiency for $\mathrm{As}(\mathrm{V})$ increased gradually up to $98,86 \%$ and $41 \%$, as the process approached the equilibrium state $(168 \mathrm{~h})$. The adsorption capacities of HFOAB, GtAB and $\mathrm{MtAB}$ for $\mathrm{As}(\mathrm{V})$ at equilibrium were $10.2,8.4$ and $2.1 \mathrm{ug} \mathrm{g}^{-1}$, respectively. In the initial stage, the higher driving force allowed external mass transfer resistances to be overcomes, and active sites with a higher affinity were occupied [19]. Once the high affinity binding sites are occupied, residual binding sites with a lower affinity become occupied, leading to the slow attainment of equilibrium.

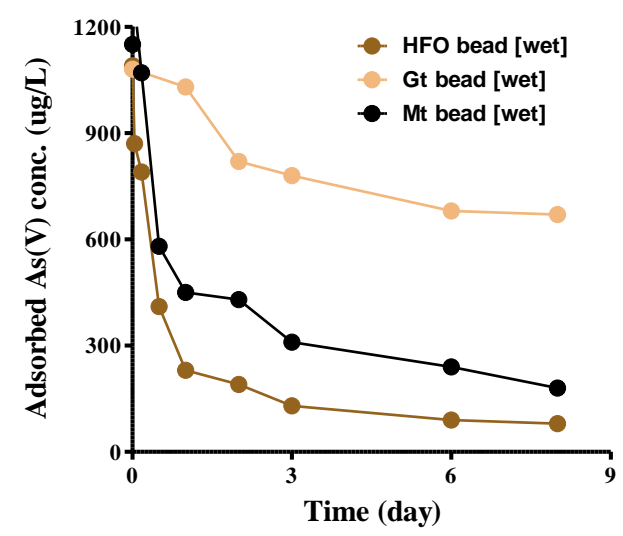

Fig. 1. Adsorption kinetics of As(V) by HFO immobilized alginate beads (HFOABs), goethite immobilized alginate beads (GtABs) and magnetite immobilized alginate beads (MtABs), respectively (Contact time: $8 \mathrm{~d}$, adsorbent amount: $10 \mathrm{~g} / \mathrm{L}, \mathrm{pH}: 5.0)$.

HFO immobilized bead was one of the promising adsorbents for removal of arsenate from the aqueous phase among the three different adsorbents.

The observed sorption capacity for $\mathrm{As}(\mathrm{V})$ sorption after drying process was comparatively higher than wet HFO beads This showed that thermal activation of beads significantly influences sorption kinetics (Fig. 2).

\section{B. Effect of Initial Concentration}


The sorption capacities of $\mathrm{As}(\mathrm{V})$ on HFOAB as a function of initial sorbate concentration were evaluated. Increase in sorption was observed with the increase in initial arsenic concentration on HFOAB (Fig. 2). An increase in the initial concentrations probably provides driving forces to overcome mass transfer resistance between solid/solution interfaces. Increase in initial $\mathrm{As}(\mathrm{V})$ concentration from 10 to $500 \mathrm{mg} / \mathrm{L}$ increased its sorption on HFOAB from 0.8 to $13.8 \mathrm{mg} / \mathrm{g}$.

\section{Effect of $p H$}

The effect of $\mathrm{pH}$ on $\mathrm{As}(\mathrm{V})$ sorption onto HFOAB was examined in the $\mathrm{pH}$ range of 4-10 (Fig. 4). As(V) species mainly exist as negatively charged, while As(III) species exist predominantly as neutral in the $\mathrm{pH}$ range of 2-10. The surface charge of the sorbent becomes less positive with increasing $\mathrm{pH}$, and the surface of the sorbent presents negative charges at $\mathrm{pH}>\mathrm{pHpzc}$

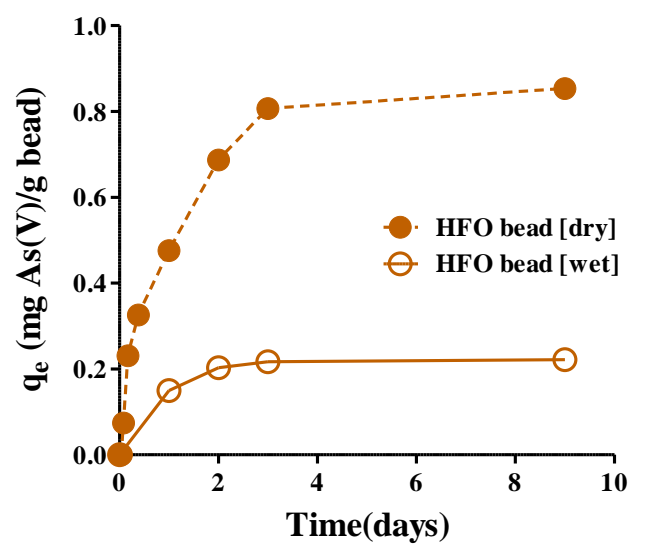

Fig. 2. Adsorption kinetics of $\mathrm{As}(\mathrm{V}) \mathrm{HFO}$ immobilized alginate beads (HFOABs) after drying process compared with wet HFOABs, respectively (Contact time: $9 \mathrm{~d}$, adsorbent amount: $10 \mathrm{~g} / \mathrm{L}, \mathrm{pH}: 5.0$ ).

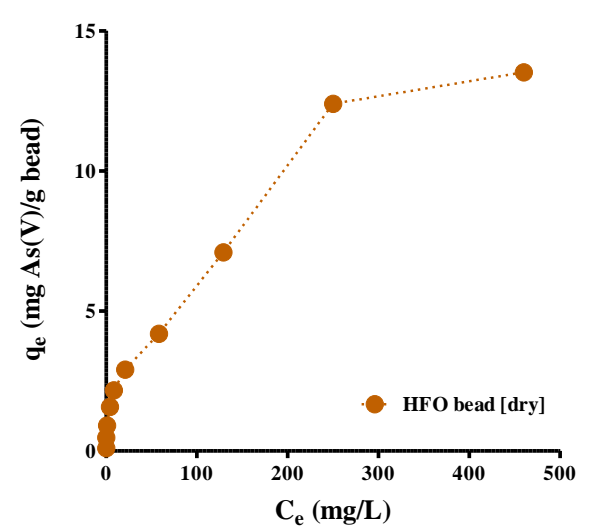

Fig. 3. Adsorption isotherm of As(V) by HFO immobilized alginate beads (HFOABs) (Contact time: 48 h, adsorbent amount: $10 \mathrm{~g} / \mathrm{L}, \mathrm{pH}: 5.0$ ).

\section{Effect of $p H$}

The effect of $\mathrm{pH}$ on $\mathrm{As}(\mathrm{V})$ sorption onto HFOAB was examined in the $\mathrm{pH}$ range of 4-10 (Fig. 4). As(V) species mainly exist as negatively charged, while As(III) species exist predominantly as neutral in the $\mathrm{pH}$ range of 2-10. The surface charge of the sorbent becomes less positive with increasing $\mathrm{pH}$, and the surface of the sorbent presents negative charges at $\mathrm{pH}>\mathrm{pHpzc}$. This phenomenon results in repulsion between sorbent and anionic sorbates. The adsorption level of As(V) was high in strongly acidic $\mathrm{pH}$ solution, in which $\mathrm{H}_{2} \mathrm{AsO}_{4}{ }^{-}$is the predominant species below $\mathrm{pH}$ 6.9. This result might be attributed to protonation of the hydrous ferric oxide surface with an abundant amount of protons $\left(\mathrm{H}^{+}\right)$, which would increase the adsorption of $\mathrm{As}(\mathrm{V})$ by enhancing the electrostatic attraction to negatively charged $\mathrm{As}(\mathrm{V})$ ions. By contrast, with a rise in solution $\mathrm{pH}$, the number of negatively charged adsorption sites increased, and the repulsion force further increased beyond $\mathrm{pH} 7$ led to a sharp decrease in the amount of adsorbed $\mathrm{As}(\mathrm{V})$ because the predominant $\mathrm{As}(\mathrm{V})$ species became $\mathrm{HAsO}_{4}{ }^{2-}$.

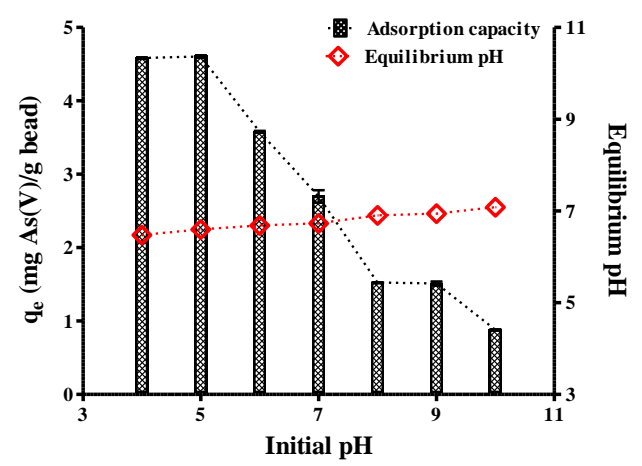

Fig. 4. Effect of $\mathrm{pH}$ on $\mathrm{As}(\mathrm{V})$ sorption onto HFO immobilized alginate beads (HFOABs), (Contact time: $48 \mathrm{~h}$, adsorbent amount: $10 \mathrm{~g} / \mathrm{L}$ ).

Substantially less adsorption of As(V) was observed at higher $\mathrm{pH}$ values, which might be due to speciation shift of $\mathrm{As}(\mathrm{V})$ to double charged $\mathrm{HAsO}_{4}{ }^{-2}$, and change of the adsorbent surface charge to negative.

\section{E. Sorption of $A s(V)$ and $C u(I I)$ in a Binary System}

The effect of the presence of $\mathrm{Cu}(\mathrm{II})$ on the adsorption of arsenic(V) species by HFOAB is depicted in Fig. 5. For adsorption of $\mathrm{As}(\mathrm{V})$ in the binary system, the effect of $\mathrm{Cu}(\mathrm{II})$ was negligible due to the characteristics of $\mathrm{As}(\mathrm{V})$ species being neutral in the wide $\mathrm{pH}$ range of 4-10. On the other hand, adsorption of $\mathrm{As}(\mathrm{V})$ distinctly increased (1.45 to 3.76) in the presence of $\mathrm{Cu}(\mathrm{II})$ ions within $168 \mathrm{~h}$. $\mathrm{Cu}$ (II) adsorption was independent of the presence of $\mathrm{As}(\mathrm{V})$, which may be attributed to the relatively faster adsorption of $\mathrm{Cu}$ (II) ions than arsenic species in aqueous phase.

\section{F. Sorption of Heavy Metals on Nano Carbon Immobilized Alginate Beads}

In order to understand the sorption mechanism and to identify the equilibration time for maximum uptake, the sorption of various heavy metal ions on ABs and NCBs was studied as a function of contact time. Fig. 6 shows the adsorption kinetics of $\mathrm{Pb}(\mathrm{II}), \mathrm{Cd}(\mathrm{II}), \mathrm{Zn}$ (II), Ni(II), Mn(II) and $\mathrm{Co}(\mathrm{II})$ on $\mathrm{ABs}$ and NCBs with $10 \mathrm{mg} / \mathrm{L}$ initial heavy metal ions concentrations. Rapid $\mathrm{Me}$ (II) sorption on both $\mathrm{NCB}$ and $\mathrm{AB}$ was observed during the initial 4 hours contact time, accomplishing 80 to $92 \%$ metals sorption. The rapid initial phase was followed by a slower phase and finally the equilibrium phase. The adsorbents exhibited an initial rapid uptake removing $90 \%$ of $\mathrm{Pb}(\mathrm{II})$ and $\mathrm{Cd}(\mathrm{II})$ within $4 \mathrm{~h}$ followed by slow kinetics that reached a plateau. $\mathrm{Pb}$ (II) and $\mathrm{Cd}(\mathrm{II})$ showed a greater sorption capacity on NCBs, which might be due to sorption sites provided by the immobilized GNC. The sorption affinity of divalent metal ions on NCB was in the following order: $\mathrm{Pb}=\mathrm{Cu}=\mathrm{Cd}>\mathrm{Zn}=\mathrm{Ni}>\mathrm{Co}>\mathrm{Mn}$. 


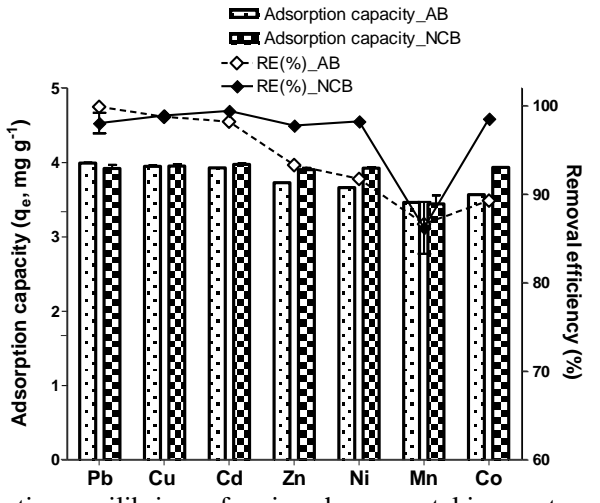

Fig. 5. Sorption equilibrium of various heavy metal ions onto nao-carbon immobilized alginate bead (Contact time: $24 \mathrm{~h}$, adsorbent amount: $2.5 \mathrm{~g} / \mathrm{L}$, pH: 5.0).

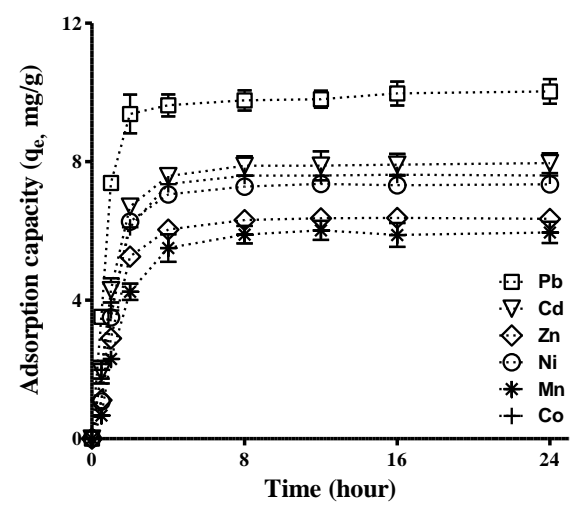

Fig. 6. Sorption kinetics of various heavy metal ions onto nao-carbon immobilized alginate bead (Contact time: $24 \mathrm{~h}$, adsorbent amount: $2.5 \mathrm{~g} / \mathrm{L}$, $\mathrm{pH}: 5.0)$.

\section{CONCLUSIONS}

An adsorbent for the efficient removal of arsenate from an aqueous phase was synthesized by immobilizing hydrous ferric oxide into alginate beads (HFOAB). The maximum sorption capacities of HFOAB for $\mathrm{As}(\mathrm{V})$ was $13.8 \mathrm{mg} \mathrm{g}-1$. a lower $\mathrm{pH}$ resulted in increased adsorption of arsenic. The simultaneous removal of arsenic and copper using synthesized $\mathrm{ZOAB}$ was possible. $\mathrm{As}(\mathrm{V})$ and $\mathrm{Cu}(\mathrm{II})$ were sorbed onto different sorption sites. The addition of $\mathrm{Cu}(\mathrm{II})$ contributed to increased positive charge on the sorbent surface, which proved to be more favorable for $\mathrm{As}(\mathrm{V})$ sorption. In summary, an adsorbent prepared using hydrous ferric oxide and alginate beads can be an efficient material for the simultaneous removal of cations and anions from aqueous solution.

\section{ACKNOWLEDGMENTS}

This subject is supported by Korea Ministry of Environment (MOE) as "Algae monitoring and removed to utilized R\&D substantiation Project" (2015001800002)

\section{REFERENCES}

[1] S. K. Papageorgiou, F. K. Katsaros, E. P. Kouvelos, J. W. Nolan, H. L. Deit, and N. K. Kanellopoulos, "Heavy metals sorption by calcium alginate beads from Laminaria digitate," Journal of Hazardous Materials, vol. 137, pp. 1765-1772, 2006.

[2] Y. Ge, Z. Li, Y. Kong, Q. Song, and K. Wang, "Heavy metal ions retention by bi-functionalized lignin: Synthesis, applications, and adsorption mechanisms," Journal of Industrial and Engineering Chemistry, vol. 20, pp. 4429-4436, 2014.
[3] L. Jin and R. Bai, "Mechanisms of lead adsorption on chitosan/PVA hydrogel beads," Langmuir, vol. 18, pp. 9765-9770, 2002.

[4] P. L. Smedley and D. G. Kinniburgh, "A review of the source, behaviour and distribution of arsenic in natural waters," Applied Geochemistry vol. 17, pp. 517-568, 2002.

[5] B. K. Mandal and K. T. Suzuki, "Arsenic round the world: A review," Talanta, vol. 58, pp. 201-235, 2002.

[6] Y.-M. Zheng, L. Yu, D. Wu, and J. P. Chen, "Removal of arsenite from aqueous solution by a zirconia nanoparticle," Chemical Engineering Journal, vol. 188, pp. 15-22, 2012.

[7] H. Cui, Y. Su, Q. Li, S. Gao, and J.K. Shang, "Exceptional arsenic (III,V) removal performance of highly porous, nanostructured $\mathrm{ZrO} 2$ spheres for fixed bed reactors and the full-scale system modeling," Water Research vol. 47, pp. 6258-6268, 2013.

[8] S. Dixit and J. G. Hering, "Comparison of $\operatorname{arsenic}(\mathrm{V})$ and arsenic(III) sorption onto iron oxide minerals: Implications for arsenic mobility," Environmental Science and Technology, vol. 37, pp. 4182-4189, 2003.

[9] A. Haug and O. Smidsrod, "Selectivity of some anionic polymers for divalent metal ions," Acta Chem. Scand, vol. 24, pp. 843-854, 1970.

[10] S. K. Papageorgiou, F. K. Katsaros, E. P. Kouvelos, J. W. Nolan, H. L. Deit, and N. K. Kanellopoulos, "Heavy metals sorption by calcium alginate beads from Laminaria digitate," Journal of Hazardous Materials, vol. 137, pp. 1765-1772, 2006

[11] S. K. Papageorgiou, E. P. Kouvelos, E. P. Favvas, A. A. Sapalidis, G. E. Romanos, and F. K. Katsaros, "Metal-carboxylate interactions in metal-alginate complexes studied with FTIR spectroscopy," Carbon Research, vol. 345, p. 469, 2010

[12] S. K. Papageorgiou, E. P. Kouvelos, and F. K. Katsaros, "Calcium alginate beads from Laminaria digitata for the removal of $\mathrm{Cu}^{+2}$ and $\mathrm{Cd}^{+2}$ from dilute aqueous metal solutions," Desalination, vol. 224, no. 1-3, pp. 293-306, 2008.

[13] S. K. Papageorgiou, F. K. Katsaros, E. P. Kouvelos, and N. K Kanellopoulos, "Prediction of binary adsorption isotherms of $\mathrm{Cu}^{2+}$, $\mathrm{Cd}^{2+}$ and $\mathrm{Pb}^{2+}$ on calcium alginate beads from single adsorption data," Journal of Hazardous Materials, vol. 162, pp. 1347-1354, 2009.

[14] C. P. Athanasekou, S. K. Papageorgiou, V. Kaselouri, F. K. Katsaros, N. K. Kakizis, A. A. Sapalidis, and N. K. Kanellopoulos, "Development of hybrid alginate/ceramic membranes for $\mathrm{Cd}^{2+}$ removal," Micropor. Mesopor. Mater, vol. 120, no. 1-2, pp. 154-164, 2009.

[15] S. K. Papageorgiou, F. K. Katsaros, E. P. Favvas, G. E. Romanos, C. P. Athanasekou, K. G. Beltsios, Tzialla, and P. Falaras, "Alginate fibers as photocatalyst immobilizing agents applied in hybrid photocatalytic/ultrafiltration water treatment processes," Water Research, vol. 46, no. 6, pp. 1858-1872, 2012.

[16] K. Hristovski, A. Baumgardner, and P. Westerhoff, "Selecting metal oxide nanomaterials for arsenic removal in fixed bed columns: From nanopowders to aggregated nanoparticle media," Journal of Hazardous Materials, vol. 147, pp. 265-274, 2007.

[17] K. D. Hristovski, P. K. Westerhoff, J. C. Crittenden, and L. W. Olson, "Arsenate removal by nanostructured $\mathrm{ZrO} 2$ spheres," Environmental Science \& Technology, vol. 42, pp. 3786-3790, 2008

[18] S. H. Kim, K.-H. Lee, D.-H. Kim, J.-P. Park, J.-H. Kim, and S.-Y. Cho, "Formaldehyde removal efficiency using nano-size carbon colloids," Indoor and Built Environment, vol. 21, pp. 837-844, 2012.

[19] V. K. Gupta, A. Rastogi, and A. Nayak, "Biosorption of nickel onto treated alga (Oedogonium hatei): Application of isotherm and kinetic models," Journal of Colloidal and Interface Science, vol. 342, pp 533-539, 2010.

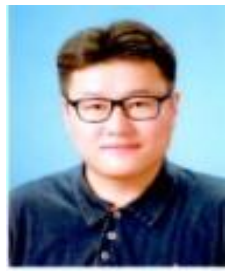

Woosik Jung was born on April 25, 1980, in Changwon, Korea. He received the bachelor of engineering in environmental engineering, Inje University, Gimhael, Korea; the doctor of philosophy in environmental engineering, Yonsei University, Seoul, Korea; and the post doctoral researcher in natural resources and environmental engineering, Hanyang University, Seoul, Korea. He now studies the Post doctoral Researcher in Korea Institute of Construction Technology (KICT), Goyang, Korea.

Dr. Woosik Jung is a researcher of water treatment, who is a researcher at Korea Institute of Construction Technology (KICT), Korea. His early research focused on soil and groundwater remediation, environmental geochemistry and water treatment process using various solid phase materials; his current interests and research is control and removal of green algae from the water treatment plants using dissolved air flotation. 